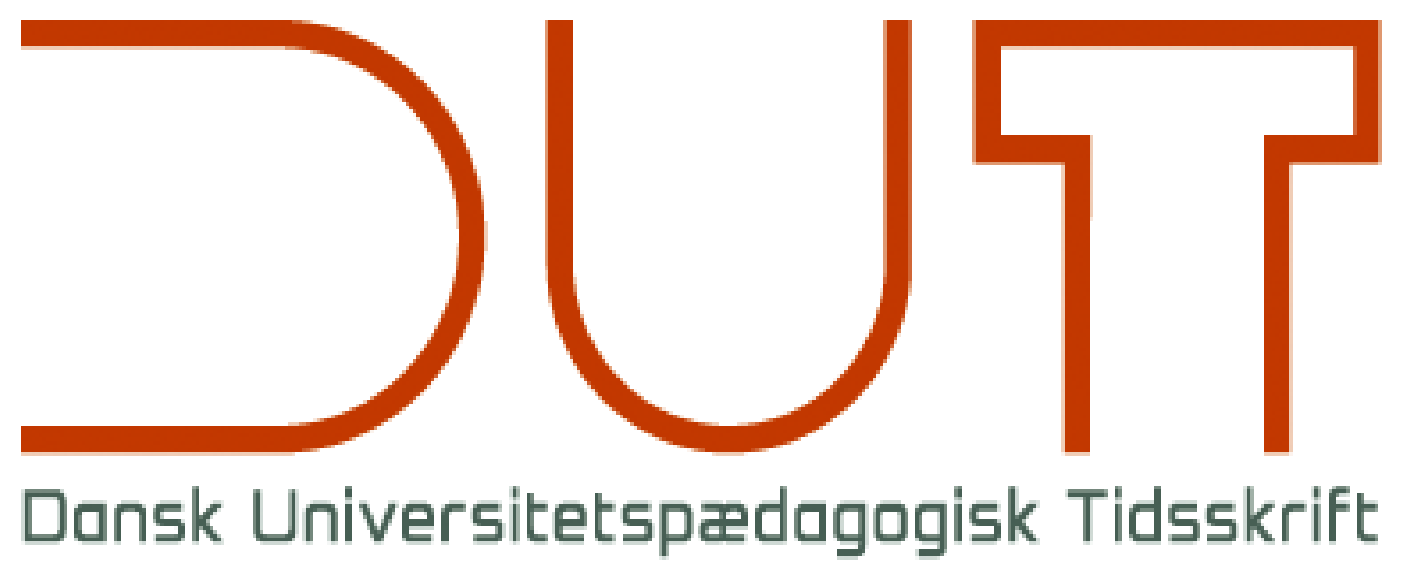

Universitetspædagogikum

Årgang 13 nr. 25 / 2018

Titel

A Virtual Veterinary Emergency Clinic - investigation of students' perceptions and self-efficacy beliefs

Forfattere

Sidetal

Udgivet af

URL

Rebecca Langhorn, Charlotte R. Bjørnvad, Anne Marie Fog-Larsen, Jakob L. Willesen, Michael May og Rikke Langebæk

$120-133$

Dansk Universitetspædagogisk Netværk, DUN

> http://dun-net.dk/

Betingelser for brug af denne artikel

(C) Copyright
Denne artikel er omfattet af ophavsretsloven, og der må citeres fra den. Følgende betingelser skal dog være opfyldt:

- Citatet skal være i overensstemmelse med "god skik"

- Der må kun citeres „i det omfang, som betinges af formålet"

- Ophavsmanden til teksten skal krediteres, og kilden skal angives ift. ovenstående bibliografiske oplysninger.

DUT og artiklens forfatter 


\section{A Virtual Veterinary Emergency Clinic - investigation of students' perceptions and self-efficacy beliefs}

Rebecca Langhorn, DVM, PhD, Assistant Professor, Department of Veterinary Clinical Sciences, University of Copenhagen

Charlotte R. Bjørnvad, DVM, PhD, Professor, Department of Veterinary Clinical Sciences, University of Copenhagen

Anne Marie Fog-Larsen, DVM, Senior veterinarian, Department of Veterinary Clinical Sciences, University of Copenhagen

Jakob L. Willesen, DVM, PhD, Associate Professor, Department of Veterinary Clinical Sciences, University of Copenhagen

Michael May, PhD, Associate Professor, Department of Science Education, University of Copenhagen

Rikke Langebaek, DVM, PhD, Associate Professor, Department of Veterinary Clinical Sciences, University of Copenhagen

\section{Research article, peer-reviewed}

At the University of Copenhagen, companion animal emergency medicine is taught in a clinical environment after students' completion of basic theoretical and clinical courses. Students are often anxious about emergency shift participation and the prospect of being the responsible veterinarian in emergency situations. This study aimed to investigate whether inclusion of virtual patients in addition to reallife patients would increase students' perceived self-efficacy in emergency medicine. Sixty-seven students were divided into two groups, one of which participated in regular emergency rotations, while the other also learned in a Virtual Emergency Clinic (VEC). Participating students were given a questionnaire regarding course experience and self-efficacy, with responses on a 10-point Likert scale. The VEC group expressed a higher level of knowledge and significantly higher level of exposure to and ability to handle emergency patients. In addition, virtual problembased learning appeared to increase veterinary students' self-efficacy with regard to managing emergency patients in their future careers.

\section{Introduction}

Companion animal emergency medicine is the study of critical illness, its diagnosis and therapy in dogs, cats and exotic pets. In general, this topic is taught in a clinical environment, and students must complete basic theoretical and clinical courses before participating in emergency situations. However, the transition from theory to 
practice is never an easy one to undertake, and emergency medicine poses a special challenge in this regard. Students may be theoretically equipped for clinical work, but, in the emergency room setting, they must be able to take immediate action, mastering the necessary skills as well as having the theory present in mind. The lifeor-death nature of the work is stressful, and many students are, therefore, anxious about emergency shift participation and the prospect of being the responsible veterinarian in similar situations in the near future once they graduate. In a learning situation this is critical, as stress and anxiety can have a negative impact on learning (Evans, Gerlach, \& Kelner, 2007; Eysenck, 1979; Fredrickson \& Branigan, 2005). Accordingly emergency medicine is an area of work in which the student must acquire self-efficacy in order to not fear the tasks they face. The theory of self-efficacy (also known as mastery expectations) refers to a student's own expectation of whether or not he/she has the competences to succeed in a given assignment (Bandura, 1977, 2012). Working towards specific goals and having a satisfactory amount of time to achieve them has been demonstrated to increase self-efficacy in the student (Schunk \& Mullen, 2012). Therefore, creating an emergency medicine course with an environment that nourishes self-efficacy is a goal worth pursuing.

At the Department of Veterinary Clinical Sciences, University of Copenhagen, companion animal emergency medicine is taught in a fourth and fifth year master course and is one of the department's core courses during which students are introduced to practical work in the clinic.

The overall learning objectives of the course are for the student to achieve knowledge, skills and competences for examining, diagnosing and treating critically ill animals. To achieve these aims the course has a practical part in which the individual student participates in day, evening and night shifts at the emergency service of the University Hospital for Companion Animals (UHCA) under guidance of a qualified veterinarian. Prior to course participation, students have completed all basic theoretical clinical courses of veterinary medicine and are, therefore, theoretically equipped for clinical work. The course strives to create a setting in which the student's opportunity to gain self-efficacy is optimized by setting specific goals: performing a problem-oriented medical work-up, reaching a diagnosis and setting up a treatment plan for their patients. However, because of the nature of the emergency situation, there is a great variety in the number and type of patients the individual student is presented with during the course. Consequently, some students may qualify as veterinarians without having had any experience with certain critical diseases in dogs and/or cats. For the new graduate, this is an unsatisfactory, stressful and potentially dangerous situation that must be considered pedagogically, so that students can graduate with the necessary level of knowledge, experience and selfefficacy. 
Thus, in order to provide students with access to the most relevant companion animal critical cases, a virtual emergency clinic was created at UHCA where the actual practical emergency shifts take place.

The so-called virtual clinic is a relatively new phenomenon in veterinary education (de Bie \& Lipman, 2012). It can best be described as a traditional problem- (and paper-) based case simulation, which has evolved into an interactive, computer-based scenario. Thus, in the virtual clinic, the program simulates clinical scenarios, in which the learner acts as the veterinarian, gathering information (history, clinical findings), diagnosing and treating (Huang, Reynolds, \& Candler, 2007). To our knowledge, only a few veterinary virtual clinics deal with emergency cases (Dale, Mcconnell, Short, \& Sullivan, 2005; Schlachter, 2004), which is unfortunate, as one of the advantages of simulation is the ability to provide a stress-free learning environment, something that the real-life emergency clinic lacks.

The aim of this study was to investigate whether inclusion of virtual patients in addition to the real-life emergency patients at the UHCA would lead to an increase in students' perceived self-efficacy in dealing with emergency patients.

\section{Materials and methods}

\section{Setting}

The study took place at UHCA during the fourth and fifth year master course, 'Emergency Medicine, Obstetrics, Critical Care, and Clinical Anesthesiology' (EOCA), prior to and following curricular implementation of the Virtual Emergency Clinic (VEC). The emergency medicine rotation within this course consists of 1) an introduction week, during which 30-40 students participate in lectures and skills lab practice and 2) one week of companion animal emergency clinical work during which one or two students at a time participate in day, evening and night shifts. During the nine-week course, there are eight individual emergency rotations in total. The EOCA course is offered twice per semester and has a written final exam (multiple choice). The study was carried out during two of the courses provided in 2015.

\section{The Virtual Emergency Clinic}

The VEC was developed as an online case-based training simulation in the open source Content Management System (CMS) Drupal (www.drupal.org). Drupal is based on a 'core' system for development of interactive web sites that can be extended through a large number of add-on 'modules'. In the VEC we have, for instance, extended the core systems with functionality for image galleries and for zooming large images (e.g. to allow for examination of X-ray images). Another module records the choices students take when requesting more information about a case, and examining and diagnosing the animal. When the student has completed 
the case, he/she will be presented with an overview of the time spent and actions taken.

The VEC is set up to mimic the UHCA where the real-life emergency shifts take place. Thus the VEC has a reception area, a consultation room, a pharmacy, an intensive care unit, imaging unit, anesthesia unit, surgical unit, etc. with photos of these locations from the actual hospital. The student acts as the veterinarian in charge with full responsibility for the (virtual) emergency patients. The patients must be examined, diagnosed and treated. For each patient a medical history is provided, and, while the student does not physically examine an actual patient, he/she gets access to the clinical findings that a proper clinical exam would result in. Subsequently students must apply their theoretical knowledge and carry out a diagnostic work-up of the patient in a problem-oriented manner, interpret test results (blood samples, radiographs, etc. which are available to the student independently of whether they are abnormal or relevant for the case), choose the proper therapeutics, provide client information and write the patient's medical record. A case may take one to two hours to complete, not unlike the time spent on the initial work-up of a patient in the clinic. At the end of the course the students receive a synopsis for each case in which the patient's diagnosis is revealed, and the hospital's suggestion for a correct patient workup is provided. The student can then compare this synopsis with their own medical record for the patient. At present, no individual, personal feedback is provided, but students are encouraged to ask instructors for elaboration on their results.

\section{Participants}

Twenty-nine students participated in the first EOCA course in the spring of 2015 and were designated to the 'No VEC' group. This group completed the course in the traditional manner based on patient intake in the hospital and with no access to the VEC. Thirty-eight students participated in the second EOCA course and were designated to the 'VEC group'. During the introduction week, a thorough demonstration of the elearning program was given, and written instructions were supplied. Each student was to access the VEC on-line and complete four virtual patient cases, write a medical record for each case and send these to the course instructor before the end of the rotation. Prior to the EOCA course both groups had participated in a general practice course at the same hospital, but had not yet encountered critically ill or emergency cases. All students volunteered to participate in the study, which was approved by the Veterinary Study Board at the University of Copenhagen. Three students who participated in the course prior to initiation of the study had volunteered to be interviewed before and after their course in order to clarify students' perceptions of their self-efficacy in relation to emergency medicine and to obtain information that could identify key subjects to be included in a questionnaire. 


\section{Questionnaire}

Based on findings from the interviews, a questionnaire was created (Appendix 1), including four main statements regarding issues related to course experience and to self-efficacy. Responses were given on a 10 point Likert scale, where $1=1$ don't agree at all, and 10=I fully agree. Additional questions were added in order to clarify if the two groups were comparable with regards to experience and ambition related to companion animal practice. After completion of the course exam the questionnaire was provided to all students included in the study. At the end of the questionnaire, students were free to comment and (for the VEC group) further elaborate on their perception of the VEC.

\section{Statistical analysis}

Similarity between groups was compared using a Chi Square test. The Likert scale scores of the two groups, 'VEC' and 'No VEC' regarding the four main statements were compared using a Mann Whitney $U$ test. Statistical significance was defined as $\mathrm{P}<0.05$.

\section{Results}

Based on the results regarding experience and interest in companion animal practice, group comparability was considered acceptable (Table 1).

\begin{tabular}{|l|c|c|c|c|}
\hline Student group & No VEC & VEC & X2 (df) & P value \\
\hline $\begin{array}{l}\text { Number of } \\
\text { students }\end{array}$ & 29 & 38 & & \\
\hline Response & $16 / 29(55.17 \%)$ & $26 / 38(68.42 \%)$ & $1.234(1)$ & 0.267 \\
\hline $\begin{array}{l}\text { Prior companion } \\
\text { animal practice } \\
\text { experience }\end{array}$ & $3 / 16(18.75 \%)$ & $3 / 26(11.54 \%)$ & $0.421(1)$ & 0.517 \\
\hline $\begin{array}{l}\text { Interest in work- } \\
\text { ing with compan- } \\
\text { ion animals }\end{array}$ & $9 / 16(62.5 \%)$ & $13 / 26(50 \%)$ & $0.155(1)$ & 0.694 \\
\hline
\end{tabular}

Table 1. Study groups VEC and No VEC: Companion animal experience and interest. VEC = virtual emergency clinic; $X 2$ = chi square statistic; $d f=$ degrees of freedom.

Results from the questionnaire's four statements are illustrated in Figure 1-4. For each statement, students expressed their level of agreement on a scale from 1-10. 


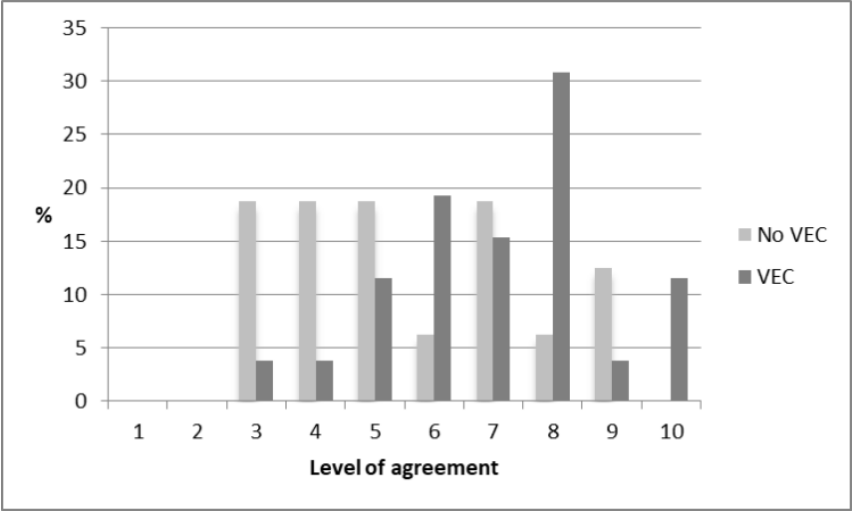

Figure 1. Students' level of agreement with the statement: I have been introduced to a wide range of emergency patients.

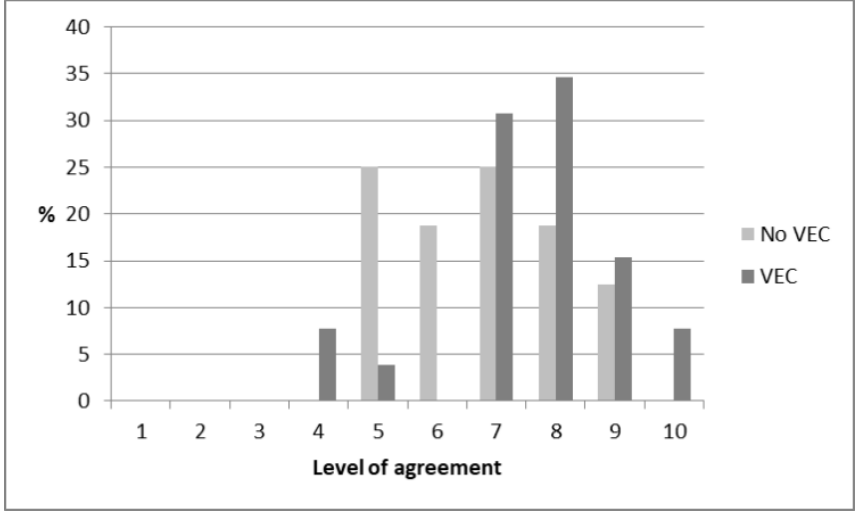

Figure 2. Students' level of agreement with the statement: I have gained knowledge of how to approach the emergency patient.

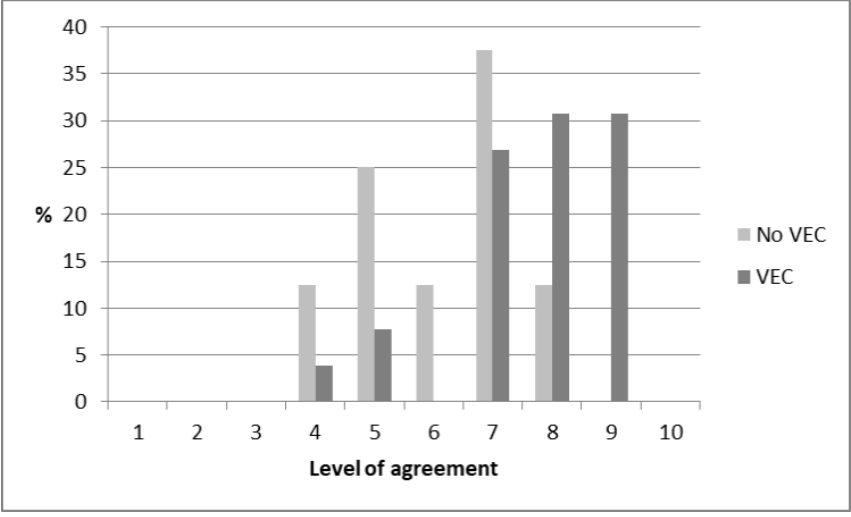

Figure 3. Students' level of agreement with the statement: I feel ready to handle emergency patients under supervision. 


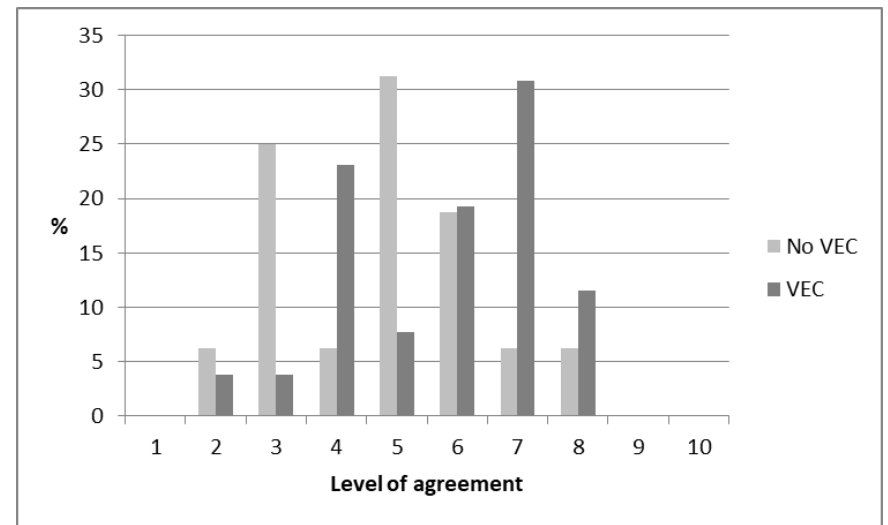

Figure 4. Students' level of agreement with the statement:

I feel ready to handle emergency patients as a qualified veterinarian.

In all four statements we found a shift towards a higher level of agreement when students had access to the VEC (Table 2).

\begin{tabular}{|l|c|c|}
\hline Statement & Median (range) & P value \\
\hline $\begin{array}{l}\text { 1) I have been introduced to a wide range } \\
\text { of emergency patients }\end{array}$ & $\begin{array}{c}\text { No VEC: 5 (3-9) } \\
\text { VEC: 7 (3-10) }\end{array}$ & 0.025 \\
\hline $\begin{array}{l}\text { 2) I have gained knowledge of how to ap- } \\
\text { proach the emergency patient }\end{array}$ & $\begin{array}{c}\text { No VEC: 7 (5-9) } \\
\text { VEC: 8 (4-10) }\end{array}$ & 0.061 \\
\hline $\begin{array}{l}\text { 3) I feel ready to handle emergency pa- } \\
\text { tients under supervision }\end{array}$ & $\begin{array}{c}\text { No VEC: 6.5 (4-8) } \\
\text { VEC: 8 (4-9) }\end{array}$ & 0.001 \\
\hline $\begin{array}{l}\text { 4) I feel ready to handle emergency pa- } \\
\text { tients as a qualified vet }\end{array}$ & $\begin{array}{c}\text { No VEC: } 5(2-8) \\
\text { VEC: 6 (2-8) }\end{array}$ & 0.065 \\
\hline
\end{tabular}

Table 2. Difference in level of agreement on a Likert scale in VEC and No VEC groups. VEC = virtual emergency clinic.

From a knowledge and experience point of view, the findings show that VEC group students expressed a higher level of knowledge and significantly higher level of exposure regarding the emergency patient than the No VEC students (Statements 1 and 2). From a point of view related to self-efficacy, the results demonstrate that, in general, students from the VEC group considered themselves more able to handle emergency patients, than the No VEC group students (Statements 3 and 4), the difference being significant with regards to managing patients under supervision (Statement 3).

Ten students from the VEC group had commented on their experience with the VEC. These comments can be seen in Table 3 . 


\section{Comment}

The [virtual] cases have given me the opportunity to think through even more scenarios.

The real emergency calls provided a small, but useful insight into the kind of patients you must be able to treat in an emergency situation. E-learning provided a more varied and broad picture of the acute cases.

I really liked the E-learning, because it was useful as a kind of repetition of the individual types of emergency cases, and I used that as preparation for my exam.

Nice, relevant [e-learning] cases. They took me longer than I had expected. It made me contemplate how I would approach an emergency patient (which tests and why).

E-learning cases were a really nice way to get access to some patients that you didn't necessarily meet in the emergency room!

Because I had very few patients [in the emergency room], e-learning was a very important factor, providing me with cases.

I also think the e-learning cases were useful, because they provided you with the opportunity to dig into some subjects by using e-learning instead of hard-core reading. Therefore, I would have liked a couple of more cases, so that one could learn about more subjects.

I think e-learning has been a great idea, and I'm sure it will be fine when more drugs, procedures, prices, etc., are added.

E-learning cases made you feel that you didn't miss so much!

There wasn't really any feedback, but that was okay as long as the synopses were elaborate and suggested different options regarding treatment.

The game could be improved by making it possible to see, during the existing cases, if a chosen treatment is wrong.

E-learning was mostly just practicing the problem-oriented medical record system, while at the same time one could repeat the different subjects. But it has the potential to become a fun way of learning, if - in the future - one doesn't have to write down the entire medical record, but instead could concentrate on learning the facts.

I probably should have made the cases before participating in the emergency rounds - partly because then I would have been prepared for some of the real emergency cases, partly because I would then have had the chance to ask for advice in relation to some of the [virtual] cases that I had trouble with. It would have been useful with a one-hour case session, giving us the opportunity to ask questions, because there were many questions that didn't come up until after you had worked with the cases.

If you want to use E-learning cases it's probably a good idea to improve the introduction. An improved intro with a demonstration of the different options, maybe including a specific case for practice - that would have been awesome.

Table 3. Comments by students from the VEC group. VEC = Virtual Emergency Clinic. 


\section{Discussion}

Creation and integration of a useful virtual reality simulator into a veterinary curriculum is not an easy task. The technical challenges are considerable, and uploading as well as maintenance of relevant data is a great and often on-going effort (Dhein, 2005). The pedagogical challenge is equally large. When considering the time and effort that goes into creating a virtual clinic, it is essential that the pedagogical outcome is worth it.

In the current study we aimed at increasing students' self-efficacy in dealing with companion animal emergency patients by introducing a virtual clinic into an emergency medicine course. Self-efficacy is best described as a 'situation-specific confidence' - a person's belief that he/she can perform a specific task, in this case the student's belief that he/she is able to correctly handle emergency patients. There are four main sources of self-efficacy: experiencing success, vicarious experience, verbal persuasion and a psychological factor (Bandura, 1977). In the present study the experience of success (through independently diagnosing and treating a virtual patient) and the psychological factor (doing so in an environment from which the anxiety of dealing with life and death has been removed) were the main foci for improving self-efficacy. In a learning situation, high self-efficacy is desirable because it is associated with high intrinsic motivation, an eagerness to engage in a course of action and, as a result, better performance (Bandura, 1977; Lane, Lane, \& Kyprianou, 2004; Rea, 2000). Our results demonstrate that students with access to the VEC have higher levels of self-efficacy and a perceived higher level of knowledge and experience than students without this option. Thus, the VEC seems to accommodate a pedagogical need. However, there is always a risk of a false sense of confidence, especially following the experience of success, when using simulation as a substitute for the unpredictable real-life situations (Clanton et al., 2014; de Bie \& Lipman, 2012). In view of this, it may be seen as a positive finding in our study that no students fully agreed (level 10) to the statements related to self-efficacy. There still was room for some amount of self-doubt.

Scalese and Issenberg in 2005 proposed ten features in medical simulation of which the majority must be present for effective learning to occur (Scalese \& Issenberg, 2005): a) Feedback is provided during the learning experience; b) Learners engage in repetitive practice; c)The simulator is integrated into the curriculum; d) Learners practice with increasing levels of difficulty; e) The simulator is adaptable to multiple learning strategies; $f$ ) The simulator provides clinical variation; g) The simulator is embedded in a controlled environment; h) The simulator allows individualized learning; i) Outcome measures are expressed clearly; and j) The simulator is a valid approximation to clinical practice. When evaluating the VEC the majority of features are, in fact, present, though this simulator is not adaptable to multiple learning 
strategies (e), the learner does not practice with increasing levels of difficulty in the current version (d) and no individual feedback is presently provided during the learning experience (a).

It is well-known that feedback is fundamental to learning (Hattie \& Timberly, 2007), and its lack in the VEC therefore deserves attention. The goal of feedback is to provide students with insight into their performance in order to optimize its quality (Clynes, MP \& Raftery, SEC, 2008; Cantillon, P \& Sargeant, J, 2008). According to Ovando (1994) feedback should be 'relevant, immediate, factful, helpful, confidential, respectful, tailored, and encouraging' in order to obtain this goal. At this point in time VEC provides response to the students in the form of a written synopsis for each case. This not only gives the student an example of a veterinarian's problemoriented approach to the given patient, but also provides an example of a medical record in the format that students are taught in the hospital. However, although it fulfills some of the requirements of Ovando (1994), it might not be considered regular feedback. Most importantly, it is not immediate, but is uploaded to the student at a later time. The student must then compare the synopsis with their own medical record in order to assess their own performance. Immediate feedback has been shown to be essential for optimal gain in game-based learning (Kili, 2005), and it is, therefore, obvious that the next step for improving the VEC is to prioritize inclusion of feedback during the training simulation. By personalizing feedback, encouraging students' progress, students would furthermore be provided with verbal persuasion, which is another source of self-efficacy, as previously mentioned (Bandura, 1977).

It would, undoubtedly, be optimal if each student was able to participate in a greater number of emergency shifts and receive more hands-on experience. In the VEC an obvious disadvantage is the lack of opportunity for the student to personally examine the patient involved. Instead the students must rely on information provided by a computer. During their clinical emergency rotations, students become part of the clinical environment and members of the emergency team, thereby developing their skills in a classical situated learning experience (Lave \& Wenger, 1991). Additionally, this provides them with vicarious experience which is also a source of self-efficacy (Bandura, 1977). Thus, the virtual patients are not a replacement for the important hands-on skills of the veterinarian, but a supplement which allows the student to work with every other aspect of clinical work in different patients, be it choice of diagnostics/therapeutics or interpretation of test results. From the findings in this study, including students' comments, it is clear that the VEC is, in fact, able to provide students with a feeling that they have encountered a wide variety of emergency cases.

Rather than simply providing these additional emergency case examples through lectures, working with virtual patients not only allows for problem-based learning (Albanes MA \& Mitchell S, 1993), but also stimulates students emotionally. Thus, sev- 
eral studies have shown that learning through simulating and playing a game adds to a student's experience of flow - an emotional state that enhances learning (Admiraal, Huizenga, Akkerman, \& Ten Dam, 2011; Beylefeld \& Struwig, 2007; Csikszentmihalyi, 1996). Achieving flow requires a balance between challenge and skill. A student's self-efficacy in a given situation depends on the perceived challenge of the assignment as well as the time provided to fulfill it. Thus, as mentioned, a benefit of the VEC is that it takes away the fear of dealing with life and death (minimizing the challenge) while keeping the responsibility of making the right decisions. This gives the student more time to think, look for guidance in the literature and make a choice in a safe environment, while gaining experience to be used when faced with a similar case in reality. Hence challenge and skill may be more balanced in this environment where the student can learn without fearing the consequences of making mistakes.

The relatively small number of students participating in this study is a limitation to take into account when drawing conclusions. The actual number of students enrolled in the course was higher (Table 1), but not all participants responded to repeated requests for them to return their completed questionnaires. The final response rate of 55-68\% was accepted for data analysis, but larger studies in the field would be desirable. Additionally, we only investigated the students' perceived level of knowledge. Accordingly, this study cannot conclude on the actual level of knowledge obtained after implementing the VEC. However, as our aim was to investigate the students' own learning experience rather than to assess the VEC as a tool to improve factual knowledge, this is not considered a limitation.

\section{Conclusion and perspectives}

The learning aims of the current course are for the student to achieve knowledge of as well as skills and competences for examining, diagnosing and treating critically ill animals. While the course aims to provide a good overview of these diseases theoretically, being able to identify a specific disease in a patient requires application of the theory in practice. The VEC helps fulfill the learning aims by providing the student with ample possibility to apply the theory practically, independent of the variety and number of patients they are fortunate to see on their emergency shifts, thus filling an existing void of available emergency patients.

The results of this study demonstrate that including problem-based learning in the form of a virtual clinic in the EOCA course increases the self-efficacy of Danish veterinary students for managing emergency patients under supervision during their training and indicate a similar effect with regards to patients in their future careers. We believe that this is likely to be true for veterinary students internationally. Student evaluation of the VEC revealed how it was fundamental in helping them think through the choices one must make for a given patient, how it was helpful in exam 
preparation and how it made them feel that they had not missed out on important learning situations if they happened to be on rotation on a day in which the number of emergency patients presented to the hospital was low. Thus, despite the challenges we faced when developing the simulated emergency room, and despite the obvious lack in its current form regarding feedback, it can be concluded from our study that the pedagogical outcome has been positive. This encourages us to prioritize this educational tool, add more cases and further improve the VEC so that, in the future, it will hopefully simulate the emergency room so closely that only the live animal is lacking.

\section{References}

Admiraal, W., Huizenga, J., Akkerman, S., \& Ten Dam, G. (2011). The concept of flow in collaborative game-based learning. Computers in Human Behavior, 27, 11851194.

Albanes MA, \& Mitchell S. (1993). Problem-based learning: A Review of literature on its outcomes and implementation issues. Academic Medicine, 58, 52-81.

Bandura, A. (1977). Self-efficacy: Toward a unifying theory of behavioral change. Psychological Review, 84(2), 191-215.

Bandura, A. (2012). On the functional properties of perceived self-efficacy revisited. Journal of Management, 38, 9-44.

Beylefeld, A. A., \& Struwig, M. C. (2007). A gaming approach to learning medical microbiology: students' experiences of flow. Medical Teacher, 29, 933-940.

Cantillon, P \& Sargeant, J. (2008). Giving feedback in clinical settings. British Medical Journal, 337, 1961-1968.

Clanton, J., Gardner, A., Cheung, M., Mellert, L., Evancho-Chapman, M., \& George, R. L. (2014). The relationship between confidence and competence in the development of surgical skills. Journal of Surgical Education, 71(3), 405-411.

Clynes, MP \& Raftery, SEC. (2008). Feedback: An essential element of student learning in clinical practice. Nurse Education in Practice, 8(6), 405-411.

Csikszentmihalyi, M. (1996). Flow and the psychology of discovery and invention. New York: Harper Collins. New York: Harper Collins.

Dale, V. H. M., Mcconnell, G., Short, A., \& Sullivan, M. (2005). Ten years of CLIVE (Computer - Aided Learning in Veterinary Education ) in the United Kingdom. Journal of Veterinary Medical Education, 32(1), 47-50. 
de Bie, M. H., \& Lipman, L. J. A. (2012). The use of digital games and simulators in veterinary education: An overview with examples. Journal of Veterinary Medical Education, 39(1), 13-20.

Dhein, C. R. (2005). Online small animal case simulations, a.k.a. the virtual veterinary clinic. Journal of Veterinary Medical Education, 32(1), 93-102.

Evans, K., Gerlach, C., \& Kelner, S. (2007). The brain and learning in adolescence. In B. della Chiesa (Ed.), Understanding the Brain: The Birth of a Learning Science (pp. 185-210). Paris: OECD.

Eysenck, M. W. (1979). Anxiety, learning, and memory: A reconceptualization. Journal of Research in Personality, 13, 363-385.

Fredrickson, B. L., \& Branigan, C. (2005). Positive emotions broaden the scope of attention and thought-action repertoires. Cognition and Emotion, 19(3), 313332.

Hattie, J. \& Timperley, H. (2007). The power of feedback. Review of Educational Research, 77(1), 81-112.

Huang, G., Reynolds, R., \& Candler, C. (2007). Virtual patient simulation at U.S. and Canadian medical schools. Academic Medicine, 82(5), 446-451.

Kiili, K. (2005). Digital game-based learning: Towards an experiential gaming model. Intenet and Higher Education, 8, 13-24.

Lane, J., Lane, A. M., \& Kyprianou, A. (2004). Self-efficacy, self-esteem and their impact on academic performance. Social Behavior and Personality: An International Journal, 32(3), 247-256.

Lave, J \& Wenger, E. (1991). Situated learning: Legitimate peripheral participation (Vol. 521423740). Cambridge University Press, Cambridge.

Ovando, M. (1994). Constructive feedback: A key to successful teaching and learning. International journal of Educational Management, 8 (6), 19-22.

Rea, D. W. (2000). Optimal motivation for talent development. Journal for the Education of the Gifted, 23(2), 187-216.

Scalese, R. J., \& Issenberg, S. B. (2005). Effective use of simulations for the teaching and acquisition of veterinary professional and clinical skills. Journal of Veterinary Medical Education, 32(4), 461-467.

Schlachter, J. G. (2004). Virtual veterinary emergency room: A software system that presents dynamic, interactive medical scenarios for teaching veterinary medicine. University of Georgia. 
Schunk, D., \& Mullen, C. (2012). Self-efficacy as an engaged learner. In S. Christenson, A. Reschly, \& C. Whylie (Eds.), Handbook of Research on Student Engagement (pp. 219-237). New York: Springer. 